\title{
INVESTIGATING DECISION SUPPORT SYSTEMS FRAMEWORKS
}

\author{
Roger L. Hayen, Central Michigan University, roger.hayen@cmich.edu
}

\begin{abstract}
Since the early 1970s a number of decision support system (DSS) frameworks have been formulated that describe the characteristics of DSS. This research effort examines several of those frameworks using published case-based research. The purpose is to determine whether the characteristics outlined by the frameworks are observed in these published cases. This is useful in determining those characteristics of actual DSS that lead to their classification. Overall, the research supports the framework characteristics. However, the results indicate that the source and scope of information do not have a strong relationship to the ad hoc and institutional DSS decision categories. Additional research should be conducted regarding other DSS frameworks.
\end{abstract}

Keywords: DSS, Decision Support Systems, Frameworks, Characteristics of Information

\section{INTRODUCTION}

A variety of decision support systems (DSS) frameworks have been postulated for describing the characteristics of DSS. These frameworks are helpful in organizing and identifying relationships of DSS. The frameworks have been forward looking and provide a view for assisting in their classification. Advances in computer technology are dynamic and impact information system applications including DSS. The result is a suite of DSS applications that is dynamic and constantly changing. This makes it virtually impossible to lock into a static set of DSS applications. Frequently, an application that involves decision making in any manner whatsoever is often classified as a DSS. While some DSS applications have become widely accepted, others are likely to ebb and flow with these technological changes. This dynamic nature of information systems technology in general, and DSS applications in particular, makes it difficult for chief information officers and other managers to clearly define a fixed suite of DSS applications through their characteristics. However, the identification of DSS applications is important in planning organization strategy for the deployment of information technology. This research analysis examines several frameworks to determine the efficacy of those frameworks by employing casebased research of DSS applications. The analysis is directed at supporting DSS framework characteristics by exploring actual, in-depth cases of the application of DSS. The purpose is to provide a perspective of DSS characteristics based on its actual application. The analysis is presented by first examining the definition of DSS. Then, by considering a framework of information requirements by decision categories, data are presented and analyzed from published casebased research to evaluated DSS characteristics. Lastly, the results of the findings on DSS characteristics are summarized.

\section{DEFINING DECISION SUPPORT SYSTEMS}

An operational definition of a DSS is important in identifying and categorizing DSS applications for the purpose of examining their distinguishing characteristics. For purposes of this analysis, the definition provided by Keen and Scott Morton [5] is used. A DSS is defined as the use of the computer to

(1) assist managers with their decision process in semi-structured tasks;

(2) to support, rather then replace managerial judgment; and

(3) to improve the effectiveness of decision making rather than its efficiency. (p. 1)

Others $[6,8,9]$ have also provided definitions for a DSS. Although some minor differences exist in these other definitions, an examination of those definitions reveals that overall they support the definition set forth initially by Keen and Scott Morton. Therefore, this is the operational definition used for this analysis.

Gorry and Scott Morton [4] provide a context for the semi-structured characteristic of this DSS definition. They relate the work of Simon and Newell to a framework of structured and unstructured decisionmaking processes. A fully structured problem is one where all three decision-making phasesintelligence, design, and choice-are structured. A fully-unstructured problem is one where all three decision-phases are unstructured. A semi-structured problem is one where one or two, but not all, of the decision-making phases are unstructured. They define information systems that are largely structured as Structured Decision Systems (SDS), whereas those that are semi-structured or unstructured are DSS. 
This viewpoint is reinforced and summarized by Power [8, p. 9], as any information system that is not a SDS/TPS (transaction processing system) is frequently labeled as a DSS. Therefore the definition of a DSS is qualified by (1) the categories of use and (2) movement along the structured/unstructured continuum. Furthermore, DSS can be divided meaningfully into two categories: institutional DSS, which deal with decisions of a recurring nature (repetitive), and ad hoc DSS, which deal with specific decisions which are not usually anticipated or recurring (one-shot) [2, 5, p.58].

For purposes of this analysis, the DSS application is distinct from the DSS tool. The DSS tool, also known as a DSS generator, is the computer software that is used in the creation of a specific DSS application. The tool is the enabling technology. The application is the specific system that actually accomplishes the work and supplies a decision maker with the required information. This is also known as a specific DSS. The DSS area has undergone profound structural changes including its technology tools [3]. Today's DSS utilize a variety of computer-based tools that make it possible to create more advanced DSS applications. An information system tool that at one time is used with a primary focus for building an ad hoc DSS may at a later time find its use as primarily an institutional DSS. Because the tool was initially created for use in building an ad hoc DSS does not imply that all information systems subsequently created using that tool are DSS. The fundamental definition of a DSS needs to be applied in determining whether or not the application is indeed a DSS.

\section{FRAMEWORKS}

A framework is useful in that it assists in gaining a perspective on the field of DSS and serves as a powerful means of providing focus on their characteristics. A number of frameworks for DSS have been reported. According to Sprague [9], a development framework is "helpful in organizing a complex subject, identifying the relationships between the parts, and revealing the areas in which further developments will be required" (p.6). These frameworks are useful in determining the parameters that are measured for each DSS examined in this research investigation.

The work of Gorry and Scott Morton [4] is a classic reprint of their original work written in 1971. They indicate the usefulness of a framework is that it "....allows an organization to gain perspective on the field of information systems and can be a powerful means of providing focus and improving the effectiveness of the systems effort." That framework provides a number of parameters (Table 1) that are DSS characteristics. Additional support for this framework is provided by Adam, Fahy, and Murphy [1], who, after considerable evaluation of multiple viewpoints, concluded that the Gorry and Scott Morton framework stands as it was originally developed in 1971. That framework continues to provide significant guidance in the study and application of DSS applications.

Table 1. Information Requirements by Decision Category

\begin{tabular}{lll}
\hline $\begin{array}{l}\text { Characteristics of } \\
\text { Information }\end{array}$ & $\begin{array}{l}\text { Operational } \\
\text { Control }\end{array}$ & $\begin{array}{l}\text { Strategic } \\
\text { Planning }\end{array}$ \\
\hline Source & Largely internal & External \\
\hline Scope & $\begin{array}{l}\text { Well defined, } \\
\text { narrow }\end{array}$ & Very wide \\
\hline $\begin{array}{l}\text { Level of } \\
\text { Aggregation }\end{array}$ & Detailed & Aggregate \\
\hline Time Horizon & Historical & Future \\
\hline Currency & Highly current & Quite old \\
\hline Required Accuracy & High & Low \\
\hline Frequency of Use & Very frequent & Infrequent \\
\hline
\end{tabular}

Source: Gorry, G. A., \& Scott Morton, M. S. (1989). A framework of management information systems. Sloan Management Review, 13(1), 51.

Donovan and Madnick [2] describe a framework that supports various managerial activities. They divide DSS into two meaningful categories of institutional DSS and ad hoc DSS. Institutional DSS are most appropriate for operational control activities, whereas ad hoc DSS are most useful for strategic planning. An area of overlap occurs in regard to managerial control applications.

The development approach used with the deployment of a DSS provides a framework for the creation and ongoing maintenance of the DSS. The systems development life cycle (SDLC) and prototyping are the main development strategies employed in constructing a DSS $[6$, p. 452-455; 8, p. 61-63]. The development strategy will be considered as one of the parameters to be investigated.

In summary, these frameworks provide the foundation for parameters that are analyzed in this investigation. Use of these frameworks provides a strong foundation for the measurement parameters of this investigation. The frameworks are examined to determine the primary attributes to be included when 
reviewing DSS cases applications or use cases. Using published research that describes DSS applications, the attributes are recorded for each case. This provides a research database of specific DSS applications.

\section{METHODOLOGY}

The research methodology is founded on the basic premise that decision support systems constitute a significant, continuing frontier in the application of computer technology in organizations. Characteristics of specific DSS are examined using a published casebased research approach methodology. A case-based research approach provides a means for investigating phenomenon in information systems in their original context and is particularly appropriate for exploratory studies [11]. Applied to DSS and related information systems, case-based research provides a method for studying the characteristics of these applications. For this research investigation, these cases are drawn from published research regarding DSS. Characteristics of each case are recorded with particular attention to information characteristics identified from the frameworks.

According to Voss, Tsikriktsis and Frohlich [10] and Meredith [7], case-based research is one of the most powerful methods in the development of generalizable conclusions about a field of study. The results of case-based research can have a very high impact that leads to new and creative insights into a field of study with a high validity with practitioners the ultimate user of research. DSS is a very dynamic field in which new applications and practices are continually emerging and changing. Case-based research provides an excellent means of studying the framework characteristics. Overall, case-based research observations can be used to assess DSS frameworks.

\section{RESEARCH ANALYSIS}

A total of 45 case-based research DSS applications were found by conducting a comprehensive literature search. Each of these provided a substantial description of their use. The characteristics of each application case were recorded, based on the parameters derived from the frameworks. Microsoft Excel and SAS Institute JMP software were used to analyze these data. No quota or other preset limit was established for the number of ad hoc or institutional cases included in this investigation. Therefore, the values for these major groupings of DSS are considered representative.
From the definition of DSS, several general characteristics were analyzed. There was a nearly even split between the ad hoc cases (53 percent) and the institutional cases (47 percent). Nearly all of these specific DSS (96\%) were developed using prototyping, whereas the system development life cycle (SDLC) was used for the other developments (4\%), and these were all institutional DSS. So, essentially all the observed cases were developed using prototyping. This suggests that the SDLC has no significant use in the development of DSS, regardless of the type of DSS application. Several other overall characteristics of the evaluated DSS were observed. This includes a measure of the extent of the structure of the decision. Of the observed cased, 69 percent were determined to be semistructured and 27 percent were structured (Figure 1). All ad hoc DSS were semi-structured, whereas all the structured were included in the Institutional DSS category (Figure 2).

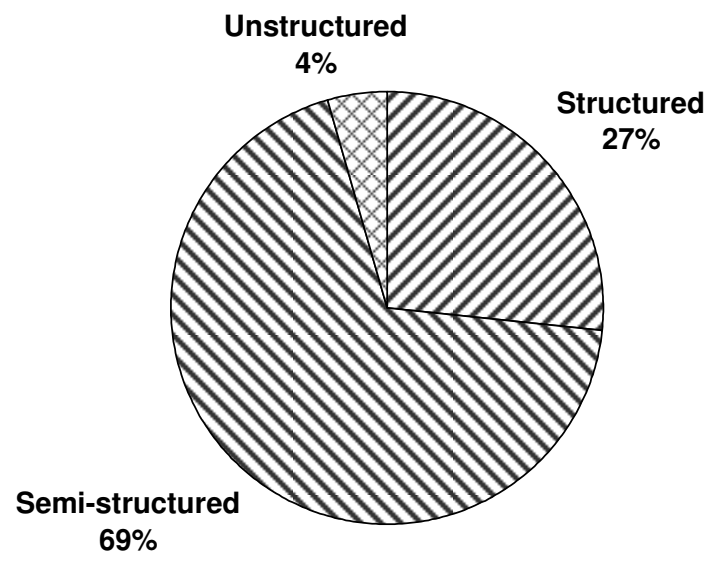

Figure 1. Decision Structure

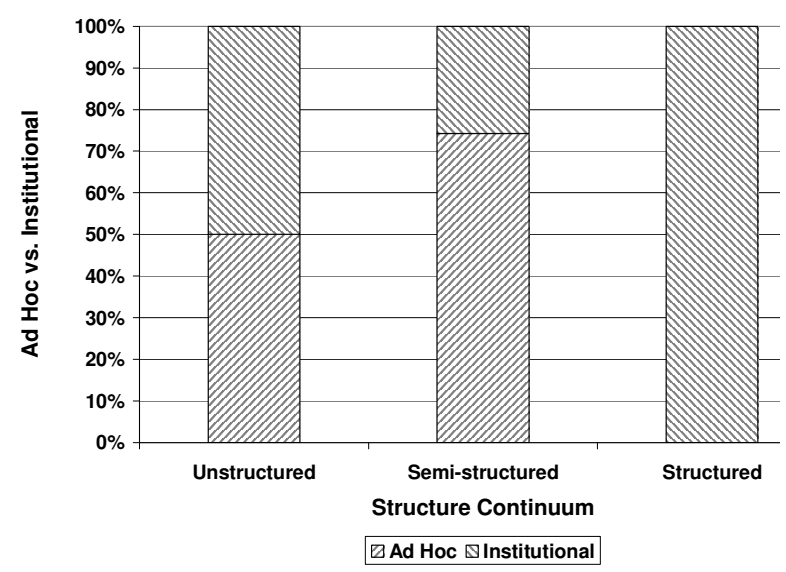

Figure 2. Decision Type versus Structure Continuum 
The primary type of DSS application was observed for the use cases. Modeling (47 percent) and expert systems (24 percent) (Figure 3) are the most frequently occurring type of DSS applications. The occurrences of these two categories of applications over time indicate that modeling case applications have been reported in a continuous stream from 1972 forward. On the other hand, expert systems applications were reported from the period of 1988 to 1996. This suggests that a rise and fall in the application of expert systems in DSS occurred during that time period.

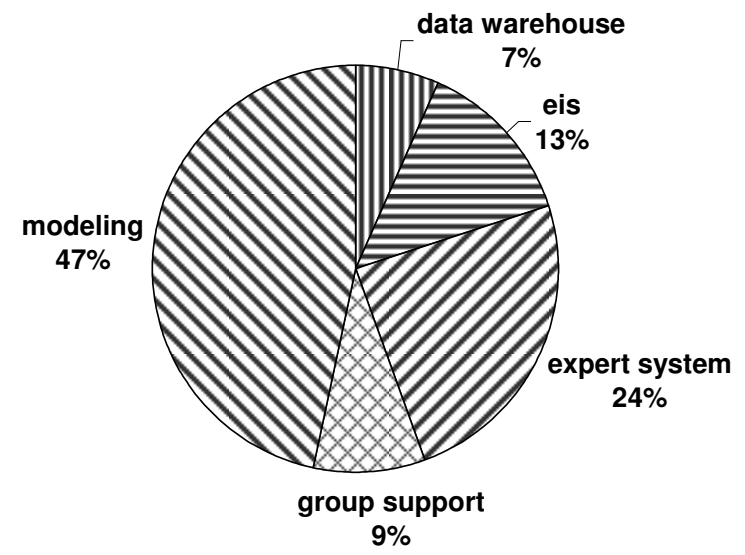

Figure 3. Type of Application

The framework set forth by Gorry and Scott-Morton (Table 1, presented above) was examined using the characteristic data collected on the observed application cases. The purpose of this evaluation was to confirm the information characteristic requirement set forth in that framework. For the purpose of this investigation, the operational control level was recorded as an institutional DSS, whereas the strategic planning level was recorded as an ad hoc DSS. This framework was examined first by using neural network exploratory modeling to determine if the framework characteristic could serve to predict the category of the application as either ad hoc or institutional. The first neural network model include all the characteristics of the Gorry and Scott-Morton framework. The result (Model One) was a neural network model that was not significant $(\chi, \mathrm{p}$ $=0.12865)$. Because the neural network Model One was not significant, each of the characteristic parameters was evaluated individually to determine the relationship between the ad hoc/institutional categorization and the characteristic using a pair-wise analysis with the results in Table 2 . The occurrence of both the source of information and the scope of information did not produce a significant relationship. This suggests that both ad hoc and institutional DSS make equal use of internal and external information and that both are as likely to have a narrow or a wide scope of information. Therefore, it is unlikely these two characteristics distinguish ad hoc from institutional application. And, further, both categories are about equally likely to include the information component represented by these characteristics.

Table 2. Significance of Information Characteristics

\begin{tabular}{|l|l|l|}
\hline $\begin{array}{l}\text { Characteristic of } \\
\text { Information }\end{array}$ & $\begin{array}{l}\boldsymbol{\chi}, \\
\text { probability }\end{array}$ & $\begin{array}{l}\text { Significant } \\
\text { at 0.05 } \\
\text { p-Value }\end{array}$ \\
\hline Source & 0.7724 & No \\
\hline Scope & 0.5644 & No \\
\hline Aggregation Level & $<0.0001$ & Yes \\
\hline Time Horizon & 0.0037 & Yes \\
\hline Currency & 0.0041 & Yes \\
\hline $\begin{array}{l}\text { Required } \\
\text { Accuracy }\end{array}$ & $<0.0001$ & Yes \\
\hline Frequency of Use & $<0.0001$ & Yes \\
\hline
\end{tabular}

Using the same procedure, each of the other characteristics was examined individually against the ad hoc/institutional decision type. Figures 4 and 5 together with Table 2 present the results of that analysis. Each of these information characteristics is significantly related to ad hoc and institutional DSS. Therefore, these characteristics appear to distinguish ad hoc and institutional DSS. As a result, the source and scope were removed as characteristic parameters for the neural network Model Two. The result was a significant model $(\chi, \mathrm{p}=0.02981)$ for predicting the decision type based on the remaining characteristic parameters of this framework.

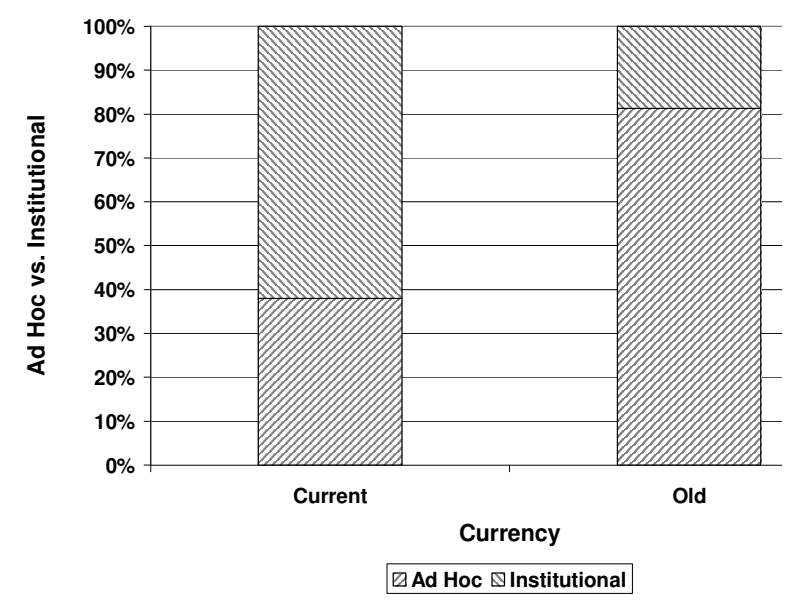

Figure 4. Currency 


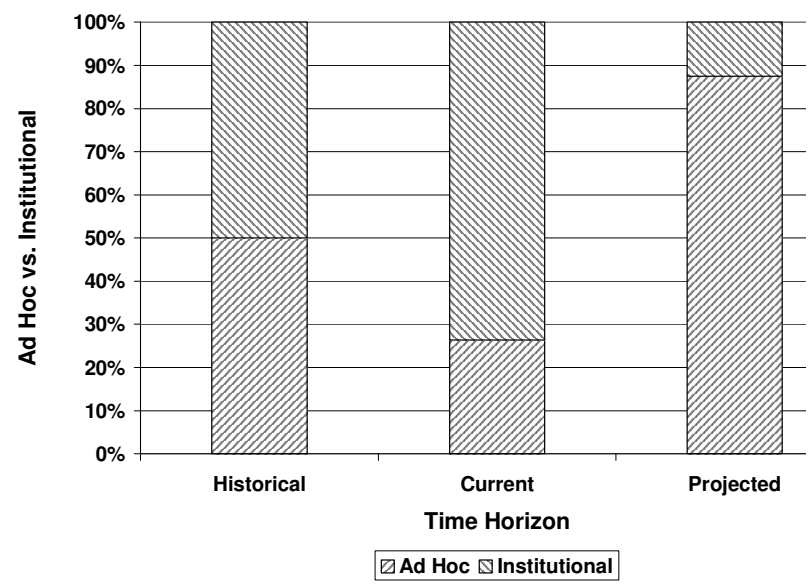

Figure 5. Time Horizon

\section{SUMMARY AND CONCLUSION}

A number of frameworks have been developed that provide characteristics of DSS. This investigation examined several characteristic parameters from these frameworks that include the structure continuum, ad hoc and institutional DSS, the development method used, and information requirements by decision category. The methodology used for data collection was an examination of published case-based research on DSS. In this context, published research is used to measure the actual deployment of DSS in organizations. A total of 45 case-based research studies were examined. Overall, the data support the characteristic parameters which have been set forth in the various frameworks. The information requirements by decision category were supported with the exception of the scope of information and the source of information. That is, an ad hoc or an institutional DSS is each about as likely to have an internal or an external source of information and each exhibits similar results for a narrow or wide scope of information.
This investigation examined 45 case-based research studies. Future analyses should examine more casebased research studies and compare characteristic parameters found in additional frameworks for DSS.

\section{REFERENCES}

1. Adam, F., Fahy, M., \& Murphy, C. (1998). A framework for the classification of DSS usage across organizations, Decision Support Systems, 22(1), 1-13.

2. Donovan, J. \& Madnick, S. (1977). Institutional and ad hoc DSS and their effective use, Database, 8(3), 79-88.

3. Eom S. B. (1999). Decision support systems research: current state and trends, Industrial Management \& Data Systems, 99(5), 213-220.

4. Gorry, G. A., \& Scott Morton, M. S. (1989). A framework for management information systems. Sloan Management Review, 31(3), 49-61.

5. Keen, P. G. W., \& Scott Morton, M. S. (1978). Decision support systems: An organizational perspective. Reading, MA: Addison-Wesley.

6. Marakas, G. M. (2003). Decision support systems in the $21^{\text {st }}$ century (2nd ed.) Upper Saddle River, NJ: Prentice-Hall.

7. Meredith, J. (1998). Building operations management theory through case and field research. Journal of Operations Management, $16,441-454$.

8. Power, D. J. (2002). Decision support systems: Concepts and resources for managers. Westport, CN: Quorum Books.

9. Sprague, R. H., \& Carlson, E. D. (1982). Building Effective Decision Support Systems, Englewood Cliffs, NJ: Prentice Hall.

10. Voss, C., Tsikriktsis, N., \& Frolich, M. (2002). Case research in operations management. International Journal of Operations \& Management, 22(2), 195-219.

11. Yin, R. K. (1993). Applications of case study research. Newbury Park, CA: Sage Publications. 